\title{
Research on Internet Anti-monopoly Regulation
}

\author{
Xiaoyue Zhang ${ }^{1, *}$ \\ ${ }^{l}$ University of Electronic Science and Technology of China, Chengdu, Sichuan, China \\ "Corresponding author. Email: zhangxiaoyue2000@163.com
}

\begin{abstract}
Given its essential role on people's life, thriving Internet platforms have become an important target of antimonopoly supervision inside and outside China. Due to the features of the digital economy, the monopolistic behaviors of the Internet platform are categorized in the following aspects: "choice between two platforms", data manipulation, bundling software and so on. At present, there are some problems in the anti-monopoly laws and regulations on platforms, such as unclear market definition, inapplicable methods for determining market dominance, and strong concealment of market dominance abuse implemented through data and algorithms. Based on the analysis of the anti-monopoly supervision and enforcement of Internet platforms in Europe and the United States, the anti-monopoly regulation of Internet platforms in China should introduce multiple relevant market definition mechanism and market dominance judgment criteria, and improve it by means of data protection and algorithm regulation.
\end{abstract}

Keywords: Internet platform, Anti-monopoly, Market dominance, Rules and regulations.

\section{INTRODUCTION}

According to the Anti-Monopoly Guidelines on Platform Economy issued by the Anti-Monopoly Commission of the State Council in 2021, Internet platform refers to a commercial organization that realizes the interaction of bilateral or multilateral entities under the operation rules provided by certain carriers, supported by network information and data technology. [1] The emergence of digital economy and the development of new industrial chains have promoted the rapid development of Internet platforms. Quality service and low price can first be applied in the market to attract a large number of users, and then user data, huge capital and technical requirements can be employed to gain an advantage in market supply, and gradually establish a monopoly position in their respective fields. [2] But Internet platform monopoly also emerges accordingly. In April 2021, the State Administration for Market Regulation imposed an administrative penalty on Alibaba's abuse of its dominant market position, imposing a fine of 18.228 billion yuan. In 2017, the German Cartel Bureau launched an anti-monopoly investigation against Facebook, finding that Facebook used illegal terms of service to impose unfair trading conditions and constituted an abuse of its dominant market position. Monopoly of Internet platform is ubiquitous and has become an international trend. The accumulation of scale capital leads to the pool of wealth of minority groups. At the same time, the level of national income is obviously stagnant. The contradiction of the two is vicious. [3] The entry of dominant foreign companies is bound to trigger competition for local markets, limit the development of local brands and create serious employment problems. However, whether the traditional legal provisions apply to the Internet platform economy, and what is the boundary of the market influence scope of the Internet platform economy, have become the emerging issues of multiparty transnational linkage. The prosperity of Internet economy has a great impact on China's economic organization, and the maintenance of a benign business environment depends on the establishment of an effective anti-monopoly mechanism.

\section{ANALYSIS OF MONOPOLY OF INTERNET PLATFORMS}

The business model of the Internet platform is different from the "commodity sales" of the traditional industry. It directly connects the bilateral and multilateral entities, realizes the exchange between the buyers and sellers, eliminates the unnecessary intermediate links, which reflects the "bilateral market" characteristics. However, when the 
Internet platform develops to a certain scale, it will capture users, use the accumulation of user data for big data analysis and deep computer learning, and then launch value-added services and products. Through the accumulation of user data and valueadded services, the platform can maintain its market position and improve its competitive strength. [4] Thanks to the characteristics and advantages of the two-sided market, the Internet platform has a wide range of influence in the digital economy market, and thus produces new monopolistic behaviors with unique digital information. The new monopolistic behaviors implemented by Internet platforms mainly include restricting e-commerce competition, data manipulation and tie-in sales of Internet products.

\subsection{Restricting E-commerce Transactions: "one or the other"}

The Internet platform, as an intermediate bridge, plays a strong connecting role, making participants interdependent. The strength of dependence leads to the unequal position of dominating and being dominated respectively. Therefore, in order to enhance their competitiveness and reduce the market power of their competitors, Internet platforms usually focus on platform participants first. According to the Anti-Monopoly Law, the abuse of dominant market position includes the following behaviors: refusing to trade, limiting trading objects without justifiable reasons, or the designated platform abusing its management authority, and unreasonably limiting trading objects, etc.

By barring operators from opening stores on competing platforms and from participating in promotional activities on competing platforms, Internet platforms have implemented the "one or the other" strategy. The signing of the Framework Agreement of Strategic Merchants and the Joint Business Plan gives the platform the right to require established merchants not to open stores on other competitive platforms, but only to carry out online sales services within the platform. In addition, the platform also requires that merchants who are the only authorized online distributor of a brand in China should not sell online through other platforms. Such strategy enables the Internet platform to achieve exclusive management and seize market advantages. Sometimes, the platform also communicates verbally to the merchants not to sell on other business platforms directly through its workers. In addition, many Internet platforms have carried out the "618" Shopping Festival and "11.11" promotion activities to attract consumers and promote the surge of product sales. In order to compete for sales volume and expand the influence of the platform, each platform will also restrict operators to carry out promotional publicity only on the agreed platform through written or oral agreement, express or implied way. According to the investigation on Alibaba's abuse of dominant market position in 2021, verbal expression can be better executed, though less effective, given the dominant market position of Alibaba's Internet platforms and the strong dependence of operators.

\subsection{Data Manipulation}

Data and algorithms play a major role in competition among Internet platforms. Data is known as the fourth major factor of production after land, labor and capital. The operation of Internet platforms largely depends on the mining of big data and the accuracy of algorithms. However, data and algorithms, the core of the development of the new generation of information technology, are often utilized by the platform. The continuous improvement of the algorithm facilitates the processing of massive data. Consumer personal information, such as: name, gender, address, mailbox, path record, consumption record, search record, etc., is often intentionally or unintentionally used as the means of production in the Internet field. Algorithms can be used to file consumers, which helps Internet platforms to clearly identify the spending power and price sensitivity of each consumer, [5] thereby predicting their preferences and then charging individuals differently for the same service. As a result, regular customers with more purchasing power and desire tend to pay higher prices. As early as 2000, Amazon customers found that they were charging regular customers almost $\$ 4$ more for the same disc than they were charging new customers. It has been reported that in recent years, varied prices for same tour product or service based on different consumers have repeatedly appeared on China's major Internet platforms: On Tmall, customers who buy a product more often are charged more; On Qunar, a second order for the same hotel will cost more than the first one. On Didi's platform, iPhone users are charged more for hailing a taxi along the same route; In Meituan delivery platform, the delivery fee of nonVIPs is significantly lower than that of VIPs.

\subsection{Bundling Sale}

Bundling sale refers to the behavior that operators sell one product to customers on the condition that customers buy another product. The bundling sale on Internet platform mainly includes software and 
service. In the 3Q war, Tencent bundled "QQ Software Management" with QQ software without the consent of users, and "QQ Software Management" would be downloaded and installed if the QQ software was downloaded. [6] QQ, as an instant messaging software, and QQ software management belong to different software markets. The bundling sale of the two does not conform to the trading practices, nor does it conform to the consumption habits or product functions. In terms of bundled services, e-commerce companies confuse the public by using font size and vague language through page settings, or only provide bundled options to mislead consumers and impair consumers' right to know and choose. According to "the investigation report of the binding problem of Internet consumption", when booking air tickets on the platform of high-speed railway management, consumers are faced with two choices: "booking" and "general booking". The "booking" option suspected of bundling 30 yuan insurance is in larger font and marked in bold blue, while the "general booking" option is marked in small gray letters, which may mislead consumers to buy the bundling service. [7]

\section{THE DIFFICULTY OF ANTI- MONOPOLY REGULATION ON INTERNET PLATFORM}

Anti-monopoly on Internet platforms has become more difficult, showing the integration and interweaving of multiple disciplines, including economics, law and computer science. The new monopolistic behaviors under the digital economy challenge the traditional anti-monopoly, such as algorithm, data, market scope, determination of dominant market position, etc. Under the existing framework, there are still differences in the antimonopoly theories on Internet platforms.

\subsection{Definition of Relevant Markets}

The method of defining relevant markets is flawed. In the anti-monopoly law, the first thing to do is to define the relevant market to effectively identify the competitors in the relevant industry, and then compare them with the subject to be examined, so as to determine whether the subject to be examined occupies a dominant market position. The traditional definition methods are mainly demand substitution analysis and supply substitution analysis. In judicial practice, the hypothetical monopolist test (SSNIP), which raises prices, is mostly used for quantitative analysis to reduce subjective arbitrariness. The firm's products are subject to small, but meaningful, and non-temporary price increases in order to find alternative commodities and related markets, and the test is repeatedly applied to determine whether the market range is appropriate. However, Internet platforms often use "free pricing" to attract customers, where software and services are downloaded without paying any fees. If the price is raised from zero to a small positive price, it is equivalent to an infinite increase in the price growth range, which means that the characteristics of the commodity or the business model change greatly. [8] The nature of the commodity changes from free to paid, and the business mode of the operator changes from indirect profit to direct profit. Such a practice may bring nonsubstitutable commodities into the relevant market, resulting in the wrong definition of the relevant market. Moreover, given the complexity of the services and products of the Internet platform, the SSNIP approach used to define the relevant market scope of the Internet platform is difficult to define its business domain. For example, Alibaba Group Holding Co., Ltd. has not only e-commerce platforms such as Taobao and Tmall, but also logistics platforms represented by Cainiao Network and financial platforms represented by Ant Financial Services.

Secondly, due to the characteristics of bilateral marketability, the Internet platform is under the scope of multiple markets. As for Internet platform competition, on the one hand, they need to meet the demand of advertisers for the number of users on the Internet platform, and on the other hand, they need to meet the demand of users for services on the Internet platform, such as Baidu's search service and Tencent's QQ instant messaging service. Therefore, under the two-sided market characteristic, the parties to the antitrust lawsuit are in three markets: the advertising market, the plaintiff's user source market, and the defendant's user source market. The three markets are independent but interrelated, so it is particularly important to define them reasonably when judging whether they have a dominant market position. However, in judicial practice, some judicial precedents define the scope of the relevant market as a single market. The United States Supreme Court affirmed that Microsoft had a dominant position in the computer operating system market from the perspective of individual computer users. In the $3 \mathrm{Q}$ War, the courts at both levels only defined the instant messaging service market without examining related markets, and the definition of market scope was defective. 


\subsection{Determination of Dominant Market Position}

There are defects in judging whether the Internet platform occupies the dominant market position by calculating the market share. According to the Interim Provisions on the Prohibition of Abuse of Market Dominant Position, market shares can be calculated by taking into account the sales amount and quantity of a specific commodity or the proportion of other indicators in the relevant market in a certain period. [9] First of all, the traditional method considers the proportion of sales sum and sales quantity from the quantitative perspective, but the calculation standards of market share are different due to the different division of relevant market scope by different subjects. Secondly, Internet platform operators mainly adopt a skewed pricing method based on the characteristics of bilateral markets, and the "free pricing" strategy adopted in the user market challenges the way of accurately determining market share through total sales.

Arbitrary choice of Internet platform does not detract from the user's dependence on the Internet platform. Although many Internet platforms seem to be substitutable and users can switch to other Internet platforms for consumption and enjoy similar services at any time, Internet platform switching cannot have a huge impact on the dominant platforms because of the strong network benefits and user locking benefits of Internet platforms. Network benefit refers to the change in the preference of consumers for a certain product as the number of consumers is constantly changing. Locking benefits means that the products that enter the market first lock in the market by virtue of the time advantage, so as to achieve a virtuous cycle of increasing returns and eliminate competition. [10] For users, network benefits and locking benefits lead to the high cost of switching Internet platforms. Taking WeChat as an example, as real-time communication software, the more users WeChat has, the more closely it fits with the social circle of users. Therefore, it is easier to get in touch with others by using this software. In this way, WeChat has a higher value for users, and the stronger the network efficiency, the easier it is to attract new users. At the same time, for users, the circle of friends and data such as video, audio and chat records established through WeChat have important memory value and carry emotional support. Not only does it take time to restructure the social circle, but data relocation is difficult to achieve. It is precisely because of the high cost of conversion that users who seem to have arbitrary choice are locked into a particular Internet platform.

\subsection{Digital Technology and Algorithms}

In the era of Internet economy, when users trade on the Internet platform as the intermediate transaction bridge, a large amount of user data and transaction data will be generated on the platform. These data, as a new kind of production materials, make collusion presented in the form of algorithm. In 2015, Topkins, an e-commerce executive on Amazon.com, was sued by the US Department of Justice for conspiring with other e-commerce companies to fix the price of poster products through algorithms. In 2016, Uber was hit with a class-action lawsuit that accused it of using algorithms to manipulate fares and conspiring with drivers to raise fares collectively during rush hours. Algorithmic collusion can be divided into messenger collusion, hub and spoke collusion, agent collusion and autonomous collusion according to its implementation mode. [11] Different from the collusion behavior mentioned in the traditional antimonopoly law, the algorithm collusion under the background of artificial intelligence can be realized in the form of multiple types and high efficiency in the Internet platform. And because of the complexity and specialization of algorithms, algorithm collusion is difficult to be found, and it is more difficult to regulate by law. The cost of algorithm collusion is low and the margin is almost zero. Based on the universal connectedness of digital economy market, algorithm collusion can help platform operators to realize dynamic pricing of platforms. Technology itself is neutral, but the way operators use technology makes the impact of technology on market competition show bias. Therefore, on the basis of the old collusion identification system of antitrust law, how to identify algorithm collusion is urgent to be solved.

\section{ANTI-MONOPOLY PRACTICES AGAINST INTERNET PLATFORMS OUTSIDE CHINA}

In recent years, the continuous expansion of the Internet market has led to the cross-domain characteristics of the influence of platforms. The monopoly issue of Internet platform has aroused heated discussion in various countries. European and American countries, represented by the United States and the European Union, have continuously reformed the anti-monopoly regulation of platforms and strengthened the crackdown efforts, thus forming a 
relatively perfect anti-monopoly supervision system suitable for the era of digital economy.

\subsection{USA: Prudential Regulation}

In recent years, the United States has mainly adopted a prudential attitude towards the monopoly examination of Internet platforms. As early as when Internet platforms were just emerging, the United States believed that Internet platforms were only intermediaries carrying third-party content, and in order to promote the development of platforms, the Federal Communications Commission and other relevant agencies did not formulate regulations for Internet platforms. However, with the expansion of the influence of Internet platforms, such as Facebook and other platforms have been involved in the wave of interference in the election, spreading false information and anti-expression of extreme opinions, free speech in cyberspace poses a threat to the security of democratic politics. Since 2016, US politicians have agreed to strengthen the regulation of Internet platforms; In 2019, the US government launched an anti-monopoly investigation on GAFA, and released the "Investigation on Competition in the Digital Market" report in 2020, which comprehensively accused the Internet platform of stealing user privacy, inhibiting innovation and eroding entrepreneurship, and launched a large-scale nationwide anti-monopoly lawsuit based on the collected evidence.

In terms of defining relevant markets, the United States adopts the theoretical analysis of "substitutability". As long as there is substitutability, it is attributed to the same market. In Mr Gringer's case against Amazon, the judge held that online and offline goods were substitutable, and that online and offline sales were in the same market. When determining whether the Internet platform occupies a dominant position in the market, American judicial practice pays more attention to whether the platform has the ability to build market barriers and its influence on eliminating competition.

\subsection{EU: Strict Regulation}

The EU maintains a strict attitude towards antimonopoly governance in the field of digital economy, attaches importance to market competition and protects citizens' private rights from excessive infringement. The EU's protection of equal competition for SMEs and the right to privacy of citizens' data are mainly reflected in the European Convention on Human Rights, the EU Small
Business Act (2008), the General Data Protection Regulation (2013) and the Framework Regulation on the Free Movement of Non-personal Data in the EU (2018). It also promulgated and implemented antimonopoly law cases targeting Internet platforms in 2020: Digital Services Act and Digital Market Act. The EU first fined Microsoft 497 million euros in 2004 for non-competitive actions, followed by billions of dollars in fines against Intel, Google and Qualcomm in 2009, 2017 and 2018 respectively for violations of abuse of dominant market position.

The EU uses the profit-model test method to define the relevant market areas, so as to avoid the definition problem caused by the "free pricing" of the Internet platform, and at the same time adopts the substituting theory of demand and supply as a supplement. In the determination of dominance, the EU distinguishes two markets, product and region, and takes the user locking benefit, platform network benefit and buyer power evaluation into consideration. In the definition of the abuse of market dominance positioning behavior, it mainly investigates whether there is the behavior of plunder consumers: whether there is the behavior of eliminating the competitive relationship, whether there is the behavior of restricting consumers' right to choose, such as "one or the other" and so on.

\section{IMPROVING CHINA'S ANTI- MONOPOLY LAWS AND REGULATIONS ON INTERNET PLATFORMS}

By facilitating daily life and improving the efficiency of resource, the Internet platform economy has flourished. However, data aggregation makes super platforms carry out algorithm discrimination and varied prices with their own advantages, which seriously damage the interests of consumers and infringe on market stability. In view of the defects of the anti-monopoly system under the digital economy, China has started the revision of the Anti-monopoly Law, and various anti-monopoly regulations concerning the platform economy issued in recent years have responded to the monopoly problem in the development of Internet platforms. The digital economy is gradually becoming regulated. Therefore, a systematic Internet antitrust system based on guiding rules is urgently needed. 


\subsection{Comprehensive Identification Method of Market Definition}

The two-sided market characteristics of Internet market make the traditional putative monopolist test to define the relevant market seem to be inadequate. When the test method cannot reasonably define the reliable relevant market, other methods should be used to supplement it. At the same time, the profit model test method applied by the European Union can provide reference. Profit model testing is a test method to determine the relevant market through the profit model. If the profit model among different entities can be proved to be substitutable, it can be included in the same market to effectively avoid the identification difficulties caused by platform technology. However, blind copying of a certain system should be prohibited. Profit model testing, as a new method, has not been generally accepted. Moreover, the practice of dividing the market only by the same profit model and ignoring other factors may easily lead to the inaccurate definition of the relevant market. Therefore, the profit model test should also be perfected and improved continuously in the localization. [12]

\subsection{Determination of "Market Dominance" by Multiple Factors}

In the era of digital economy, the development of the Anti-Monopoly Law should be combined with the characteristics of the implementation of platform monopoly by the network platform, and user data and user loyalty of the network platform should be taken into consideration when determining the dominant position in the market. The draft amendment to the Anti-Monopoly Law affirms that the determination of market dominance requires taking into account network effects, economies of scale, locking effects and the ability to grasp and process data. This revision is in line with the characteristics of the development of the Internet platform economy and promotes the anti-monopoly law to keep pace with the era of digital economy. However, it still needs to be made clear in laws and regulations and judicial practice that the Internet market is different from the traditional market. When defining the dominant position of the market, it should be defined in a comprehensive way in the tripartite market of the platform of both parties in dispute, advertiser and user. Secondly, when considering the abuse of dominant market position, we should consider the ability and behavior of Internet platform to construct market barrier. This involves data monopoly behavior, alternative Internet platform, data discrimination, algorithm discrimination, cross-border competition caused by bundling sales, etc. In view of the advantages of the Internet platform, well-funded, numerous users and a large number of industry patent and user data, the platform operator is extremely easy in a short period of time by controlling the core intellectual property and capital to improve the market barriers, eliminate the industry competition, or make the industry cannot compete effectively at the same time introducing competitive power and influence in the field of cross-industry.

\subsection{User Data Protection}

The Internet platform makes use of the advantages of collecting user transaction data to form data monopoly, which affects market competition on the one hand and causes loss to user privacy on the other hand. Therefore, user data privacy, as the source, should be paid attention to and protected by data rules that conform to the platform's economic characteristics. Data rules should firstly classify the types of user data collection on the Internet platform, strictly supervise the data collection by grades and quantities, and carry out prohibited disclosure protection for some information related to personal rights and interests by using big data and algorithms. Secondly, it should be made clear that the acquisition, exchange, sharing and use of user data by the platform should be based on the knowledge of the group to which the data belongs. Furthermore, the data subject should be guaranteed the interactive communication right to require the Internet platform to transmit and share data to other third parties, so as to effectively break down the barrier [13] that the user data only flows within the platform or between limited platforms and effectively prevent data monopoly. Finally, it is necessary to strengthen the connection with various laws and regulations, such as the connection with the Data Security Law in the future, and give full consideration to the establishment of a system conducive to the interests of the victims in terms of the relief approaches, preservation methods, use conditions and damage compensation for the personal data privacy of users of the platform. [14]

\subsection{Perfecting Algorithm Regulation}

At present, the supervision of algorithm only stays on the advocacy slogan of value theory. However, in view of the important role of algorithm in digital economy, the regulation of algorithm should be implemented from value theory to specific legal norms, and the regulatory means and measures 
should be updated to maintain market fairness from the source.

First, algorithm is a technology in nature, and it is only an implementation mechanism to reach a collusion agreement. The identification of algorithm collusion still needs to be based on the mutual consent of both parties. At present, the Provisions on Anti-Monopoly Agreements prohibits eight ways of forming price monopoly agreements, and it is suggested to include algorithms into the scope of prohibitions. However, it excludes the behaviors that different competitors use the algorithm to rely on each other in pricing. For example, operators use the algorithm to refer to the pricing of competitors to ensure that their prices are slightly lower than those of competitors, so as to guarantee relatively high sales volume. Second, specify the types of data that the algorithm is forbidden to collect and rely on. The collection of users' personal information by the algorithm shall be based on the foregoing prohibitive provisions on user data protection, and on the maintenance of public interests and social public order and good customs. In specific fields, data such as gender, religion, race and health status shall not be used as the basis for algorithm pricing. The operating scope of prohibitive provisions should be reasonably broadened, not only applicable to Internet platform operators in a dominant position in the market, but also should be universal to all Internet platform competitors without reasonable reasons. [15] Finally, the information asymmetry of the algorithm should be eliminated. Most algorithms exist as the trade secrets of the platform and are not suitable for disclosure. Moreover, the algorithms themselves are highly professional and the general public cannot play a supervisory role. Therefore, in order to ensure the effective implementation of regulation and maintain operators' intellectual property rights, Internet platform operators should be required to disclose algorithms to specific regulatory units, and regulatory units should be equipped with corresponding technical personnel and regulatory equipment. Ensuring that regulatory capacity improves with the level of technological progress is a pressing issue.

\section{CONCLUSION}

The rapid development of Internet platforms based on digital economy has greatly enhanced the influence of platform economy. "Alternative" agreements, differential pricing and bundling sales have repeatedly violated the rights of citizens, suggesting that the current antitrust laws need to be changed for a new type of monopoly. Under the Internet platform, there are many products and most of them are priced at zero, which challenges the traditional identification method of defining the market boundary by the monopolist test. The profit model test introduced by the European Union and South Korea provides a reference for China. Under the existing framework, the multiple definition method needs to be adopted to make up for the deficiencies. Based on the unique user loyalty of bilateral market and digital economy, the absolute quantitative method of determining market dominance positioning needs to include the consideration of network, locking benefits and barrier building to judge the platform's ability to eliminate and influence competition. As the core data of the platform, the algorithm is neutral. The unreasonable use of users makes algorithms monopolistic tools of Internet platforms. At the same time, it is urgent to strictly regulate data and algorithms from the aspects of collection, disclosure and use. In the new era, the anti-regulation of Internet platform should be gradually improved through innovation, and the antimonopoly law enforcement should also cooperate with the rule of law to achieve the purpose of maintaining the order of healthy competition in the market.

\section{AUTHORS' CONTRIBUTIONS}

This paper is independently completed by Xiaoyue Zhang.

\section{REFERENCES}

[1] Anti-monopoly Guidelines of the Antimonopoly Commission of the State Council on Platform Economy, Anti-monopoly Commission of the State Council [2021] No. 1, issued on February 7, 2021. (in Chinese)

[2] Zhang Zhian, Li Hui. Global Comparison of Internet Platform Antitrust and Its Governance Path in China. News and Writing, Issue 2, 2021. (in Chinese)

[3] Liu Yun. International Trends of Online Platform Antitrust and China's Response, Tribune of Political Science and Law, Issue 6, 2020. (in Chinese)

[4] Liu Jifeng. The choice of legislation mode of anti-monopoly system on Internet platform in China. Price: Theory \& Practice. Issue 1, 2021. (in Chinese) 
[5] Cheng Shang. Antitrust Enforcement against Personalized Pricing in the Artificial-Intelligence Era from the Perspective of Big Data Discrimination. China Business and Market. Issue 5, 2020. (in Chinese)

[6] Beijing Qihoo Technology Co., Ltd. sued Tencent Technology (Shenzhen) Co., Ltd. and other companies for abusing market dominance, Guangdong Higher People's Court ((2011) Yuegao Fa Minsanchuzi No. 2 Civil Judgment). (in Chinese)

[7] See the website of Beijing Consumers Association, http://www.bj315.org/xxyw/xfxw/201910/t2019 1016_20473.shtml, last accessed on May 3, 2021. (in Chinese)

[8] Case of dispute over abuse of dominant market position by Beijing Qihoo Technology Co., Ltd. against Tencent Technology (Shenzhen) Co., Ltd. and Shenzhen Tencent Computer System Co., Ltd. Supreme People's Court Guiding Case No. 78 (2013). (in Chinese)

[9] "Interim Provisions on the Prohibition of Abuse of Dominant Market Position", State Administration for Market Regulation Order No. 11, issued on June 26, 2019. (in Chinese)

[10] Xu Guangyao. Adjusting Antimonopoly Law for Abuse of Dominant Position under Circumstance of Two-Sides Market in Internet Industry, Law Review, Issue 1, 2018. (in Chinese)

[11] Liu Jia. The Anti-monopoly Regulation of Algorithmic Collusion in Context of Artificial Intelligence, Journal of Henan University (Social Science), Issue 4, 2020. (in Chinese)

[12] Hong Xujian. Research on the Definition of Internet-related Markets, Suzhou University, 2018. (in Chinese)

[13] Sun Fangjiang. Research on the Symbiotic Development of Financial Industry and Internet Platform from the Perspective of Digital Monopolies. Southwest Finance. Issue 3, 2021. (in Chinese)

[14] Tan Jiachao, Li Fang. Anti-monopoly in Internet Platform Economy: International Experience and Countermeasures. Reform. Issue 3, 2021. (in Chinese)
[15] Shi Chunfeng. Antitrust Law Regulation of Pricing Algorithm in Online Transactions. Hebei Law Science, Issue 11, 2018. (in Chinese) 